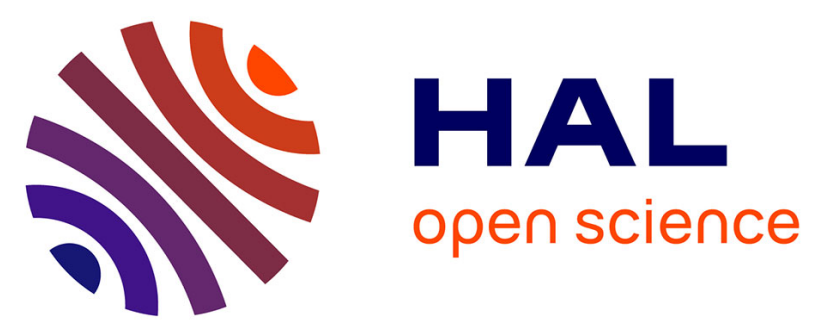

\title{
Investigation of plastic deformation heterogeneities in duplex steel by EBSD
}

\author{
S Wrońskia, J Tarasiuk, B Bacroix, A Baczmański, Chedly Braham
}

\section{To cite this version:}

S Wrońskia, J Tarasiuk, B Bacroix, A Baczmański, Chedly Braham. Investigation of plastic deformation heterogeneities in duplex steel by EBSD. Materials Characterization, 2012, 73, pp.52-60. 10.1016/j.matchar.2012.07.016 . hal-01193054

\section{HAL Id: hal-01193054 https://hal.science/hal-01193054}

Submitted on 4 Sep 2015

HAL is a multi-disciplinary open access archive for the deposit and dissemination of scientific research documents, whether they are published or not. The documents may come from teaching and research institutions in France or abroad, or from public or private research centers.
L'archive ouverte pluridisciplinaire HAL, est destinée au dépôt et à la diffusion de documents scientifiques de niveau recherche, publiés ou non, émanant des établissements d'enseignement et de recherche français ou étrangers, des laboratoires publics ou privés. 


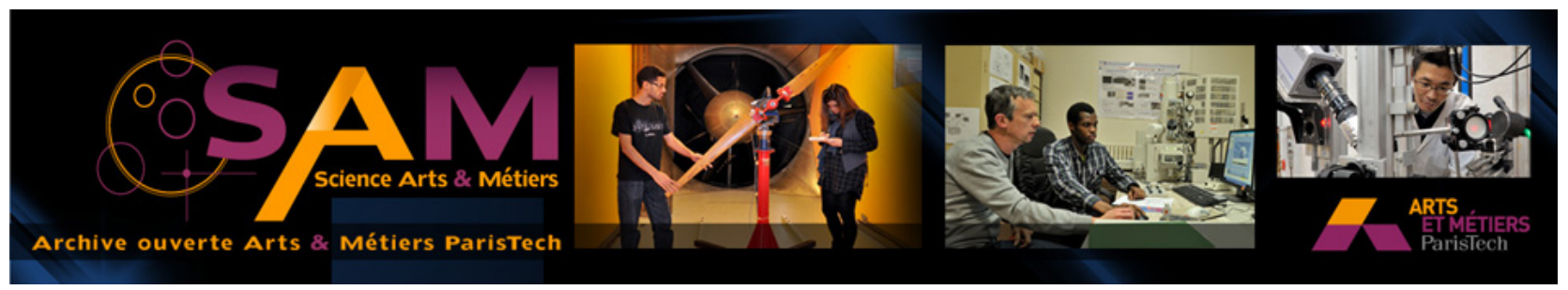

Science Arts \& Métiers (SAM)

is an open access repository that collects the work of Arts et Métiers ParisTech researchers and makes it freely available over the web where possible.

This is an author-deposited version published in: http://sam.ensam.eu

Handle ID: .http://hdl.handle.net/10985/9914

\section{To cite this version :}

S WROSKIA, J TARASIUK, B BACROIX, A BACZMASKI, Chedly BRAHAM - Investigation of plastic deformation heterogeneities in duplex steel by EBSD - Materials Characterization - Vol. 73, p. $52-60-2012$ 


\title{
Investigation of plastic deformation heterogeneities in duplex steel by EBSD
}

\author{
S. Wroński i,* , J. Tarasiuk ${ }^{a}$, B. Bacroix ${ }^{b}$, A. Baczmański ${ }^{a}$, C. Braham ${ }^{c}$ \\ ${ }^{a}$ Faculty of Physics and Applied Computer Science, AGH-University of Science and Technology, Al. Mickiewicza 30, 30-059 Kraków, Poland \\ ${ }^{\mathrm{b}} \mathrm{LSPM}-\mathrm{CNRS}$, Université Paris 13, 99, Av. J.-B. Clément, 93430 Villetaneuse, France \\ 'PIMM, Arts et Métiers ParisTech (ENSAM), 151 Bd de l'Hôpital 75013 Paris, France
}

Keywords:

\begin{abstract}
A B S T R A C T
An EBSD analysis of a duplex steel (austeno-ferritic) deformed in tension up to fracture is presented. The main purpose of the paper is to describe, qualitatively and quantitatively, the differences in the behavior of the two phases during plastic deformation. In order to do so, several topological maps are measured on the deformed state using the electron backscatter diffraction technique. Distributions of grain size, misorientation, image quality factor and texture are then analyzed in detail.
\end{abstract}

Duplex steel

EBSD

Tensile test

Texture analysis

Twinning

\section{Introduction}

The extensive range of industrial applications of duplex steels is related to their excellent resistance to corrosion and their high strength, combined with high toughness. Their advantageous mechanical properties, namely strength and ductility, are largely a result of the duplex structure, which is constituted of ferrite and austenite [1,2]. However, the morphology, repartition, and texture of both phases are also important factors which are known to control the mechanical behavior and final properties of these materials [3]. In particular, it is well-known that the two phases do not present the same mechanical behavior during deformation $[4,5]$. To date, this feature has been previously investigated mechanically by means of mechanical tests, residual stress measurements and comparison of the mechanical data thus attained, with some predictions being made with polycrystalline models. Yet all these approaches only offer limited information in respect of the local behavior of both phases. A systematic study of elastoplastic behavior of duplex steel was performed by Dakhlaoui et al. using diffraction techniques (X-ray and neutrons) [6]. Carrying out measurement under tension, important differences in the evolution of lattice strains were observed. An elastoplastic model (self-consistent) was used to predict the evolution of internal stresses during loading and to identify the critical resolved shear and strain hardening parameters for each phase within the studied duplex steel $[7,8]$. The present work is the second stage of the study and it concerns microstructure evolution during tension. The microstructure (strain heterogeneities) is of prime importance in damage and the initial crack [9]. The differences in behavior of each phase and the strain heterogeneities were studied by other authors using various techniques (SEM, TEM, EBSD, AFM)

\footnotetext{
* Corresponding author.

E-mail addresses: wronski@ftj.agh.edu.pl (S. Wroński), tarasiuk@ftj.agh.edu.pl (J. Tarasiuk), brigitte.bacroix@univ-paris13.fr (B. Bacroix), baczman@ftj.agh.edu.pl (A. Baczmański), chedly.braham@paris.ensam.fr (C. Braham).
} 
Table 1-Chemical composition (wt.\%) of examined materials.

\begin{tabular}{cccccccccccc} 
& $\mathrm{C}$ & $\mathrm{Si}$ & $\mathrm{Mn}$ & $\mathrm{P}$ & $\mathrm{S}$ & $\mathrm{Cu}$ & $\mathrm{Ni}$ & $\mathrm{Cr}$ & $\mathrm{Mo}$ & $\mathrm{Ni}$ & $\mathrm{N}$ \\
\hline UR45N & 0.015 & - & 1.6 & - & 0.001 & 0.12 & - & 22.4 & 2.9 & 5.4 & 0.17
\end{tabular}

[10-12]. Strain heterogeneities between phases in duplex stainless steel were examined experimentally during in situ test using the EBSD technique and Digital Image Correlation (DIC) [13]. The obtained results were compared with simulations made using finite elements method (FEM) by Bartali et al. [9]. All previous studies conducted by other authors have a qualitative character. The aim of this work is to describe qualitatively and quantitatively the differences in the behavior of two phases during plastic deformation using EBSD technique. This technique acquires orientation maps for a plane sample, to identify grains and sub-grains, and to study the morphology, orientation, and in the case of a multi phase material, phase geometry. The new method based on the concept initially proposed by Tarasiuk et al. [14] was used for the first time in a multiphase material. The distribution of the image quality factor was used to determine deformed and recrystallized volume fractions of a material in each phase.

\section{Experimental Procedure}

The material used in the study is an austeno-ferritic stainless steel known as URN45N, containing approximately $50 \%$ austenite and $50 \%$ ferrite. The chemical composition of this alloy is presented in Table 1. It was obtained by continuous casting, and then hot rolled down to a final thickness of $15 \mathrm{~mm}$. Before cold deformation, the URN45N alloy was solution heat-treated at $1050{ }^{\circ} \mathrm{C}$ and quenched in water in order to avoid precipitation of secondary phases. It was then annealed for $1000 \mathrm{~h}$ at $400{ }^{\circ} \mathrm{C}$ and cooled in ambient air. This temperature was chosen to avoid precipitation of an intermetallic phase rich in Ni, Si and Mo, in other words, the $\gamma$ phase [15].

A cylindrical specimen with a gauge length of $15 \mathrm{~mm}$ and a diameter of $8 \mathrm{~mm}$ was machined from a sheet, with the axis aligned along the rolling direction (RD). The sample was then deformed in tension until complete failure. Significant strain anisotropy was observed between the transverse and normal directions (see Fig. 1). The broken sample was then cut using an oil-cooled wire saw along the (RD-TD) plane for further EBSD analysis.

The EBSD maps were obtained with a Cambridge S360 (W-GUN) scanning electron microscope (SEM), equipped with automatic OIM (orientation imaging map) software from TSL at LSPM-CNRS. Three different areas, each $700 \mu \mathrm{m} \times 700 \mu \mathrm{m}$ in size, were selected in the (RD-TD) plane. The three areas corresponded to three different levels of strain (see Fig. 1), namely, no deformation, the initial state (init); an intermediate level of strain (medium); and a high level of strain (high) close to the necking region. Before measurement, the samples were mechanically polished with silicon carbide paper down to grade 4000 and then electropolished in an A3 solution produced by Struers. During the grinding and electro-polishing of the sample, a maximum thickness of $10 \mu \mathrm{m}$ was removed.

Several statistical analyses were performed on the EBSD data from each scanned area. The following list explains the significance of all the parameters used:

IQ factor (image quality) - According to the TSL software, IQ describes the quality of Kikuchi patterns. This factor may be used as an estimation of stored energy or dislocation density, as previous publications have shown $[14,16]$. The absolute value of the IQ factor depends on the experimental settings and sample preparation but the shape of the IQ distribution can mainly be attributed to variations in hardening degree or dislocation density within the area scanned. In order to compare IQ distributions for different samples and areas, this factor is normalized to a range of between 0 and 1 . It is important to reiterate that an IQ comparison of this nature is a useful method only if the relevant surface area of all the samples under study is very well prepared.

Kernel average misorientation (KAM) - The local misorientation can be characterized using a misorientation Kernel approach. For a given point, the Kernel average misorientation of that point in relation to all its nearest neighbors is calculated, with the proviso that those misorientations exceeding a given tolerance value, usually set at $15^{\circ}$, and associated with grain boundaries is excluded from the averaging procedure. It has been shown $[17,18]$ that this KAM parameter is, indeed, a good tool for determining the degree of deformation and even more efficient for determining the degree of recrystallization during interrupted
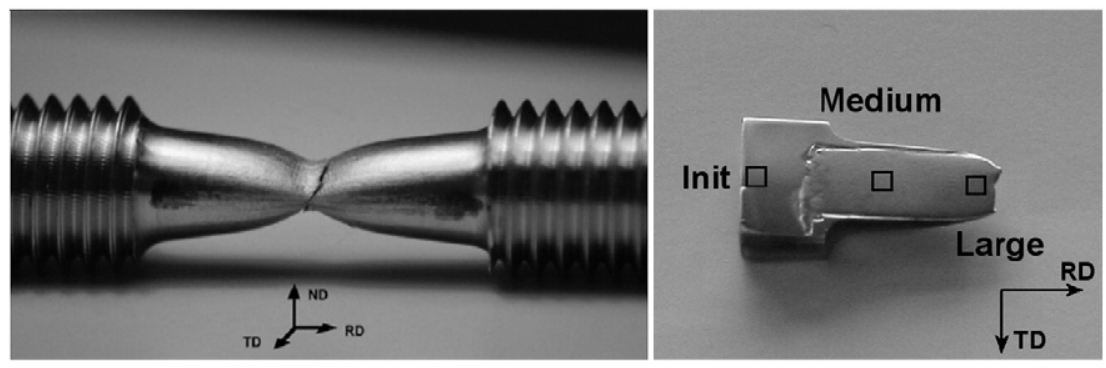

Fig. 1 - The duplex steel sample after tensile deformation (the reference sample system linked to the plane of the original sheet is shown in order to characterize the anisotropy of deformation within the neck). The large difference of deformation between TD and ND direction is clearly seen. 


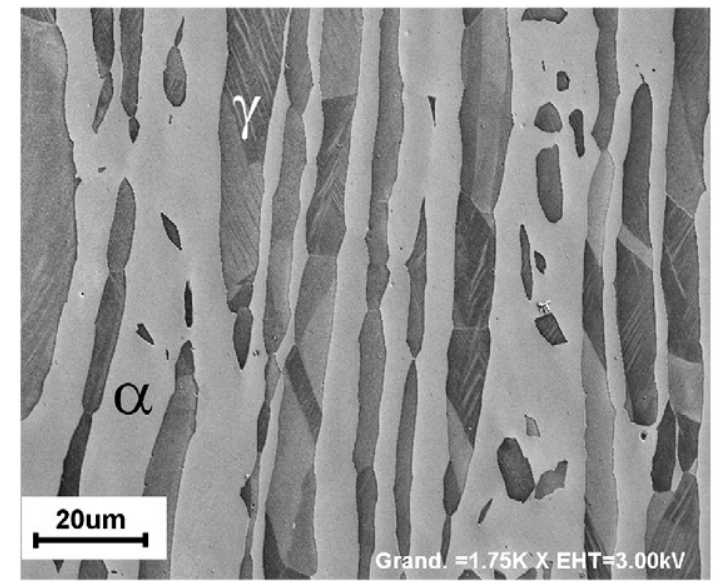

Fig. 2 - Microstructure of the studied duplex steel. Medium deformation vertical-TD, horizontal-RD.

annealing treatments. Once it has been calculated for each point within a map, it can then be averaged on all points belonging to one given phase.

Grain boundary determination based on kernel average misorientation (GBKAM) - In this case, we calculate a KAM, but without excluding the high angle misorientations. This means that all the neighboring points on the one under consideration, even those across the grain boundary and belonging to a different grain, are included in the GBKAM value. It then becomes clear that the points associated with GBKAM values higher than $10^{\circ}$ correspond quite well to the points which are close to the grain boundaries, being associated with a minimum misorientation of $15^{\circ}$. The GB areas are then more easily and completely identified than they are when only the high misorientation values, which may sometimes correspond to isolated segments, are considered.

Grain size - The grain size distribution was calculated under the assumption that the minimum misorientation characterizing grain boundaries is equal to $15^{\circ}$. The average grain size was then weighted by the grain area. According to the OIM TSL software documentation, the average grain size is calculated as:

$$
\langle A\rangle=\sum_{i=1}^{N} \nu_{i} \cdot A_{i}
$$

where: $A_{i}$ is the area of $i$-th grain and $v_{i}$ is the fraction of the whole sample taken by the $\mathrm{i}$-th grain $v_{i}=\mathrm{A}_{i} / \mathrm{A}_{\text {sample }}$.

Texture - For each sample, an orientation distribution function (ODF) was calculated from the orientation data collected by EBSD. In order to do this, a Gaussian peak was set around each measured orientation, with a Gaussian spread set equal to $5^{\circ}$. The final ODF was developed using the series expansion method up to series level 22, in line

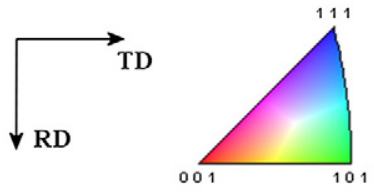

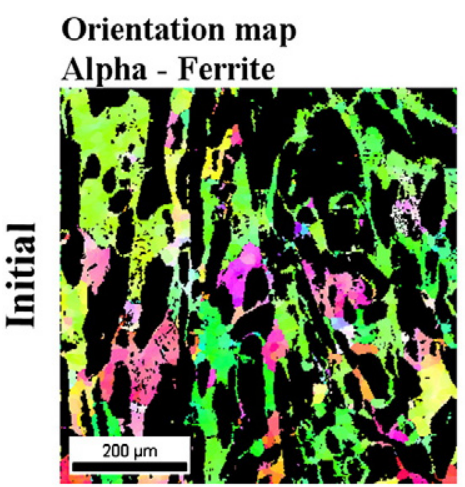

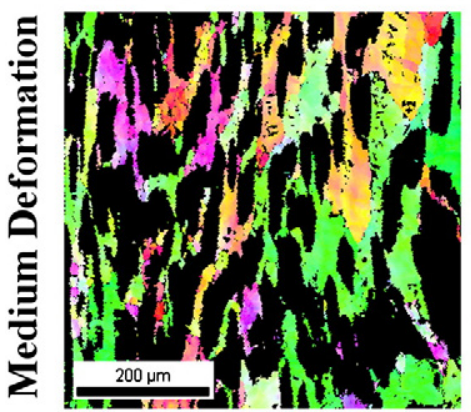

Orientation map

Gamma - Austenite
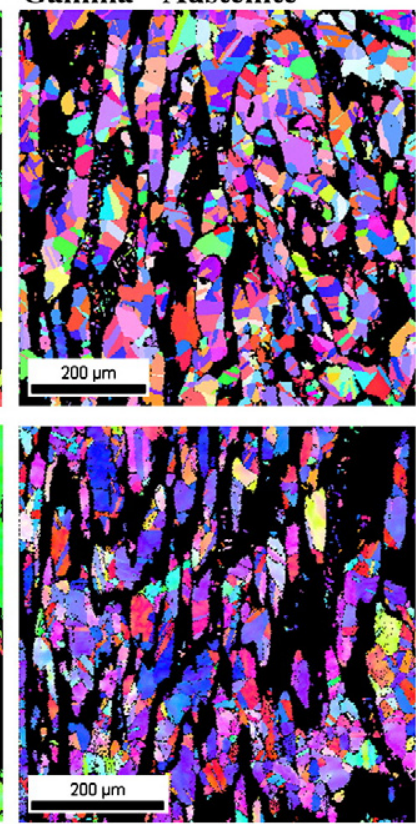

IQ map
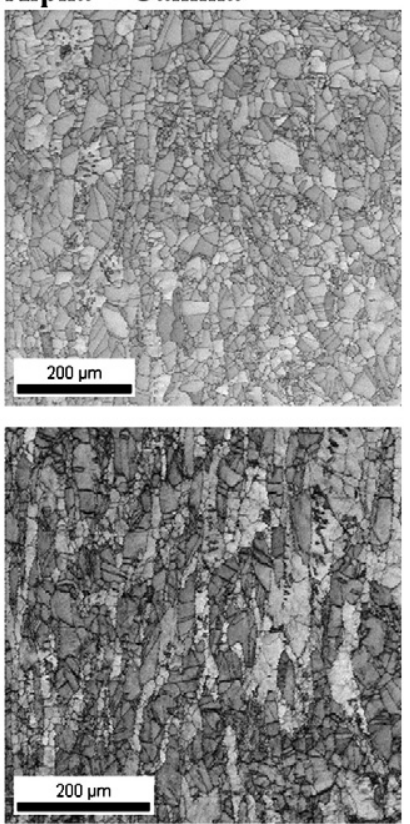

Fig. 3 - Maps of orientation and IQ distribution for two degrees of deformation. The maps obtained on the highly deformed sample are not shown for the sake of clarity but are used in the subsequent analyses. 


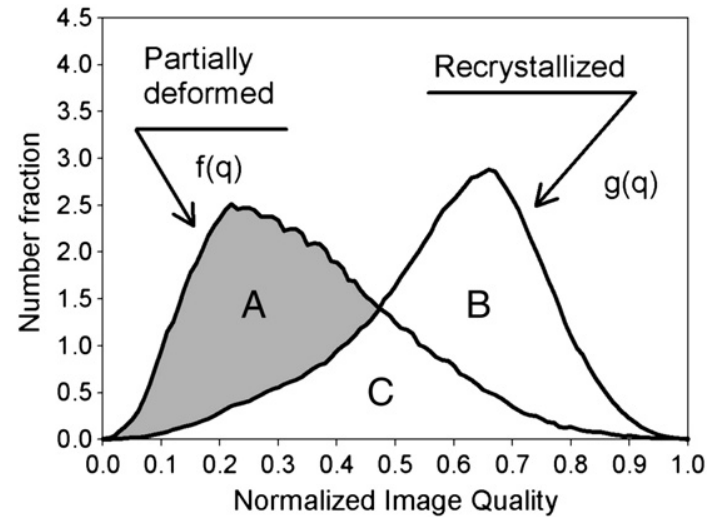

Fig. 4 - Typical histogram of image quality factor for deformed and fully recrystallized materials.

with the Bunge formulation [19] and the resulting ODF was finally calculated as the sum of all these peaks. ODF is presented in Euler space using the standard convention proposed by Bunge [20].

The volume fractions of the texture components of interest, given below, were finally calculated in accordance with the method explained in [21].

CSL (coincident site lattice) boundaries - The fraction of various coincident site lattice boundaries was calculated using the TSL OIM software.

\section{Results}

Typical microstructure, orientation and IQ maps obtained by SEM and EBSD on the sample surface are shown in Figs. 2 and 3. The characteristic microstructure consists of gamma islands, which is to say, groups of grains, elongated along the rolling direction and embedded in an alpha matrix as it was confirmed by optical methods in the previous work made on the same sample [7]. The maps show that all the crystallites of the alpha phase have almost the same orientation, while the gamma islands are divided into smaller grains, with different orientations of the lattice. A similar microstructure has previously been reported by other authors $[22,23]$.

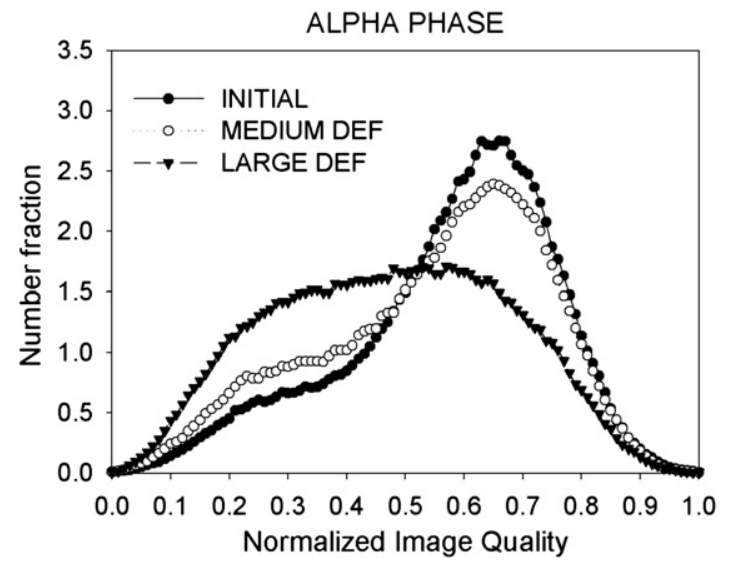

From the IQ maps presented in Fig. 3, it can be seen that, in the initial state, the IQ values are fairly similar for the gamma and alpha phases. It is also clear from the IQ maps that the level of deformation is fairly heterogeneous from grain to grain. A more quantitative analysis can be done using IQ histograms. The method used in this study is based on the concept initially proposed by Tarasiuk et al. [14]. In that paper, the distribution of the IQ factor was used to determine deformed and recrystallized volume fractions of a material subjected to different annealing treatments giving rise to partial or complete recrystallization. The general idea, which is very simple, is illustrated in Fig. 4, where the two normalized IQ distributions shown correspond to one completely recrystallized sample and one deformed sample. The total area under each curve is, by construction of these histograms, equal to one, since it includes all the points within the area under study. The superposition of these two plots can be divided into three regions. As shown in [14], region A corresponds to all the points which are deformed without ambiguity; region $\mathrm{B}$ corresponds to the points which still remain undeformed, whereas region $\mathrm{C}$ is a mixture of deformed and non-deformed points. The area of region A can then be used as an estimator of the deformed fraction in the material. This value is a minimal deformed fraction, since some points included in the uncertain region $\mathrm{C}$ can also correspond to the deformed state.

The distributions presented in Fig. 4 have been designated $\mathrm{f}(\mathrm{q})$ and $\mathrm{g}(\mathrm{q})$ for deformed and recrystallized (initial) samples respectively. The minimum deformed volume fraction can be calculated as

$$
X_{\min }=\int_{q: f(q)>g(q)}[f(q)-g(q)] d q
$$

where the integration is performed over the range of $q$ values for which $f(q)$ is greater that $g(q)$.

The IQ normalized distributions obtained for the various degrees of deformation for alpha and gamma phases are shown in Fig. 5. In both phases, deformation leads to a shift of the IQ distribution peak to the left, in other words, to lower IQ values. However, the evolution rate of these distributions is different in both phases. In the alpha phase, the shape of the IQ distribution changes rather slowly compared to the gamma phase, and the final IQ distribution is almost symmetrical to

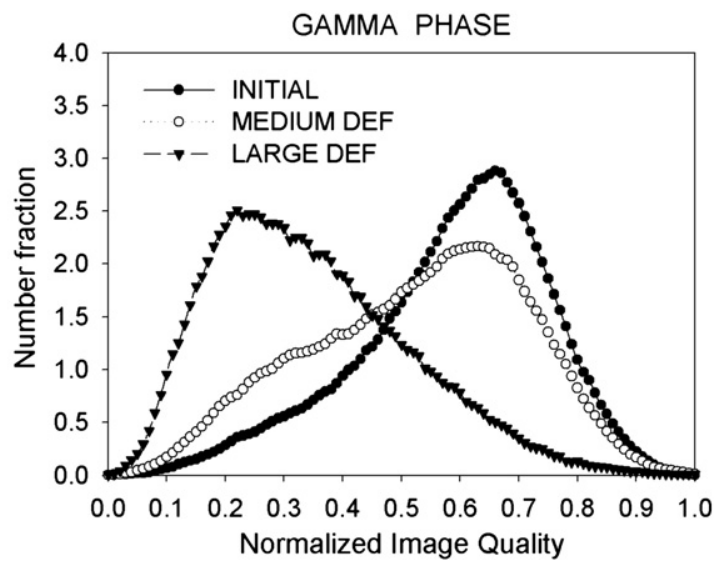

Fig. 5 - Normalized IQ distribution for various degrees of deformation for the alpha and gamma phases. 
Table 2-The minimum deformed volume fraction calculated in the two phases after different strain levels.

Degree of deformation

Deformed volume

\begin{tabular}{lcc} 
& Alpha (\%) & Gamma (\%) \\
\hline Medium & 7 & 15 \\
Large & 25 & 56 \\
\hline
\end{tabular}

the initial one with respect to the intersection point. These qualitative observations can be supported by quantitative calculations based on, for instance, Eq.(2)

The minimum deformed volume fraction was calculated by assuming that the initial state is deformation free, meaning that the deformed volume fraction is $0 \%$ in this case. The results of this calculation, presented in Table 2, show a larger deformed volume fraction in the gamma phase $[24,25]$.

The average KAM values calculated within each phase are presented in Fig. 6. It is clear that the average misorientation increases with the increasing degree of deformation, thus confirming that the internal grain structure becomes more inhomogeneous with the building up of a dislocation microstructure. It is worth noting that, in the initial state, the average KAM value is slightly higher in the alpha phase than in the gamma phase. This could be a sign of the activation of different annealing mechanisms in both phases before deformation, namely incomplete recrystallization restricted to recovery in the alpha phase and complete recrystallization through nucleation and growth in the gamma phase, as has previously been observed in a similar study [26]. During deformation, the average misorientation increases faster in the gamma phase than in the alpha, again confirming the previous conclusions, drawn from the IQ profiles, of a higher level of deformation in the gamma phase.

The internal subgrain structure was also investigated using the GBKAM parameter. On the maps presented in Fig. 7, points with a GBKAM higher than $10^{\circ}$ and corresponding to grain boundary areas are marked in red, whereas points with a GBKAM between $1^{\circ}$ and $5^{\circ}$ which correspond to the subgrain boundaries, are marked in yellow. It can be seen that, in the initial material, many low angle misorientations, in other words, those below $5^{\circ}$, are present in the alpha phase, confirming the hypothesis of incomplete recrystallization in

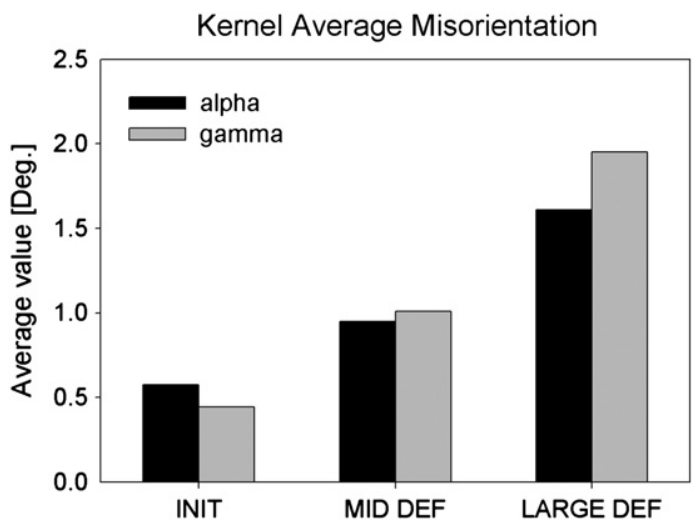

Fig. 6 - Kernel statistics for alpha and gamma phases. this phase. In the gamma phase, high angle misorientations are dominant, as expected after complete recrystallization, which led to the fragmentation of initially elongated deformed grains. In Fig. 8, the histograms of volume fractions occupied by low angle boundaries (LAB) and high angle boundaries (HAB) are shown and it is clear that the volume fraction of low angle boundaries increases with the increasing degree of deformation in both phases. This can be perceived as being the direct consequence of the building up of a dislocation microstructure composed of subgrains which can be separated by dislocation walls during deformation. However, the evolution rate of the LAB fraction within one phase may depend, in a complex way, on three main parameters. The first of these is the initial LAB fraction, which is higher in the alpha phase; the second is the level of deformation, assumed to be higher in the gamma phase; and the third is the degree of stability of the subgrains created during deformation, since, owing to deformation, initially close subgrains can reorient very differently, further increasing the misorientation between them $[27,28]$. As a consequence of these various influences, this LAB fraction first increases faster in the gamma phase, and then still more rapidly in the alpha phase. As for high angle boundaries, their fraction increases with strain in the alpha phase but not in the gamma phase. It might be suspected that this is owing to the texture evolution presented below.

The average grain size values were then examined for all samples. This parameter decreases in both phases during deformation. The alpha grains are generally bigger and reduce in size from $350 \mu \mathrm{m}^{2}$ in the initial state to $200 \mu \mathrm{m}^{2}$ for heavily deformed material. At the same time, the average size of the

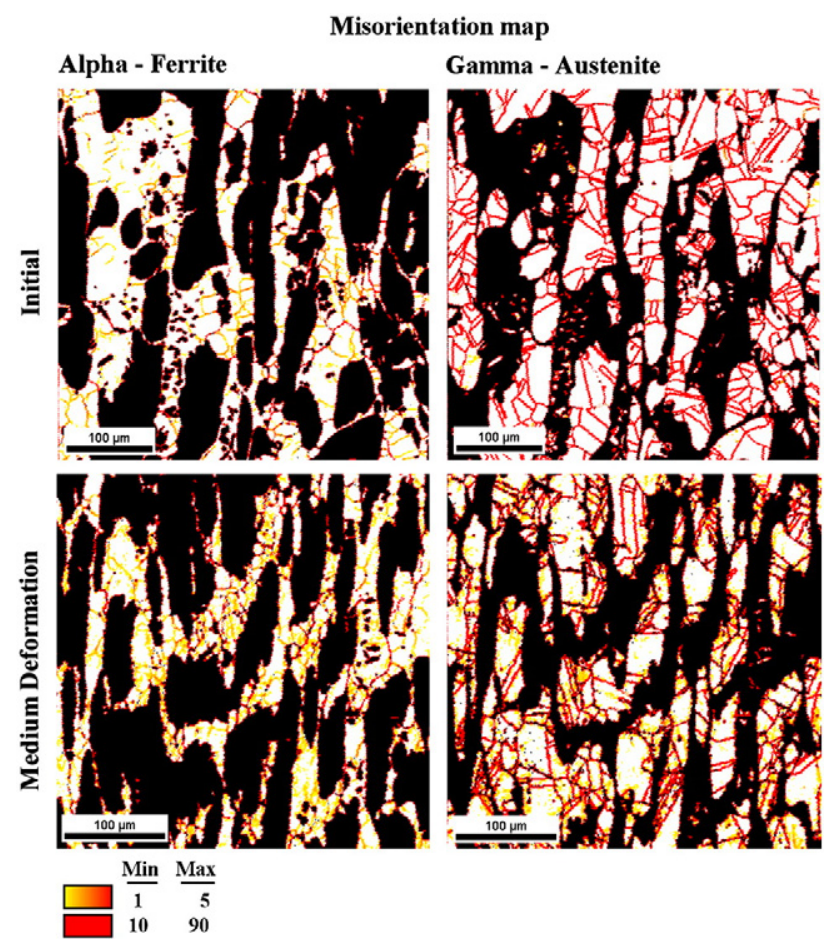

Fig. 7 - Maps of low and high angle boundaries or alpha and gamma phases, identified from GBKAM. 

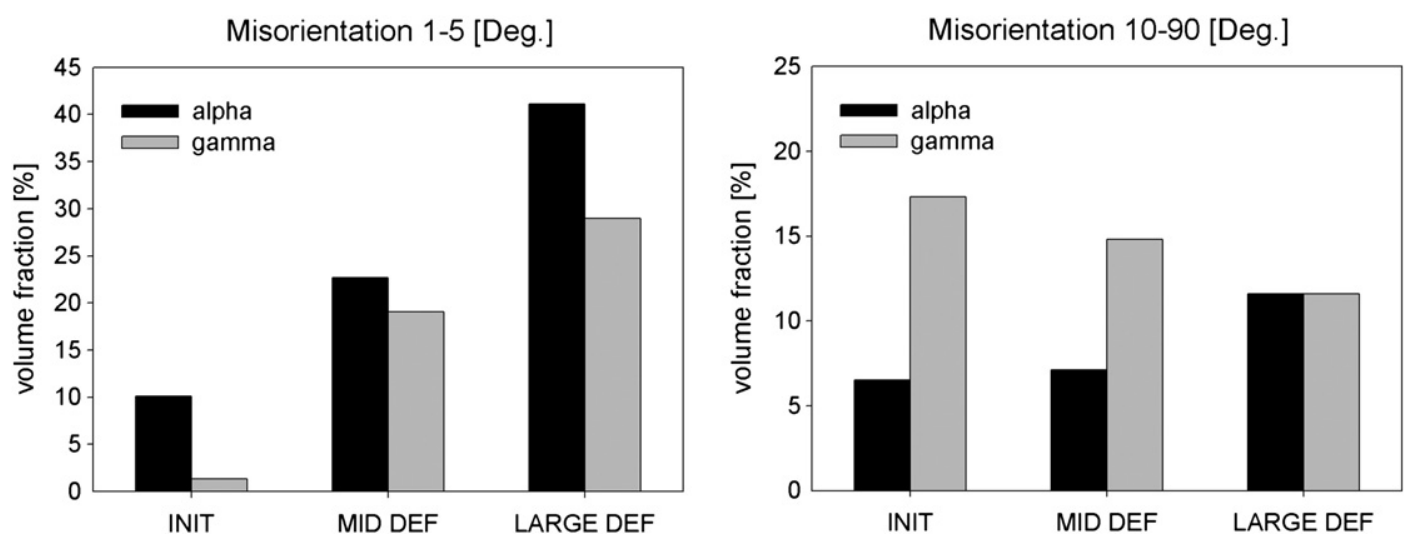

Fig. 8 - Fractions of low and high angle boundaries, calculated from the GBKAM calculations for both phases and different strain levels.
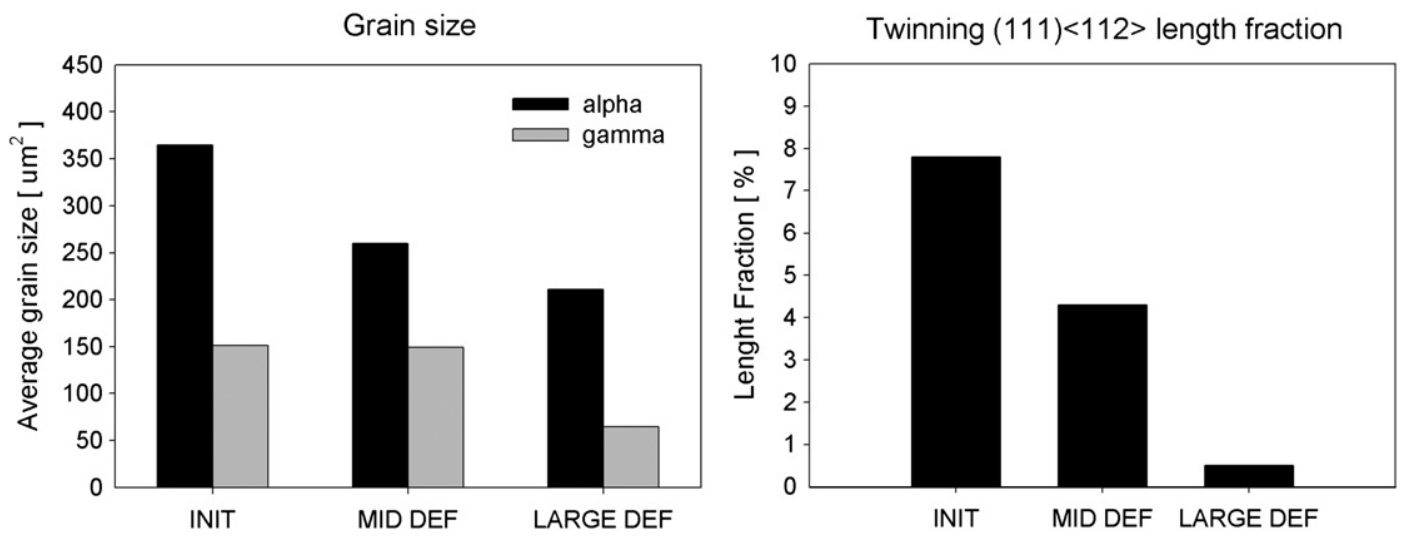

Fig. 9 - Grain size for both phases and twinning length fraction for the gamma phase.

gamma grains changes from $150 \mu \mathrm{m}^{2}$ to $50 \mu \mathrm{m}^{2}$. As regards the specific misorientations which might be present within the material, it can first be observed that $\{111\}<112>$ twins, typical for recrystallization in fcc materials, are observed in the gamma phase, whereas the alpha phase is practically free of them. The boundary length fraction of the twins decreases with increasing deformation (Fig. 9) and, as a result, almost all of them have disappeared in the highly deformed state.

The fraction of other CSL boundaries has also been examined in the gamma phase and the resulting values are presented in Table 3.

In the initial state, almost $70 \%$ of the specific boundaries are $\Sigma 3$, and are thus associated with annealing twins. As mentioned previously, this number rapidly decreases during deformation, to reach $4.2 \%$ after high deformation. The percentage of total CLS boundaries decreases simultaneously from 73 to $11 \%$. The presence of a significant amount of low $\Sigma$ CSL boundaries is worth emphasizing, since it has been shown that this could lead to higher fatigue and fracture resistance [29-31]. In the alpha phase, the total fraction of CSL boundaries between $\Sigma 3$ and $\Sigma 17$ is about $6 \%$ in the initial state and remains constant during deformation, which is more or less what is expected in an isotropic distribution of orientations.

The textures measured in both phases are presented in Figs. 10 and 11, in terms of ODF sections.

A large difference between the two phases can be seen in the texture evolution observed. The alpha phase is mainly composed of one single $\{100\}<011>$ component. Known as a rotated cube and typical of annealing in this structure (see, for instance, [26]), it is also known to be stable during tension along $\mathrm{RD}$. As a result, a reinforcement of this component on the ODF plots can be observed. The initial texture of the gamma phase is more dispersed along the so-called $\beta$ fiber, ranging from $B S=\{110\}<112>$ through $S=\{123\}<634>$ to $\mathrm{Cu}=\{112\}<111>$, which is typical for rolling and also comprises a significant proportion of the Cube and rotated Cube orientations, usually associated with recrystallization. This mixture of deformation and annealing components is also classically observed in fcc materials after rolling and annealing [17]. As, in tension, the stability components are the $<100>$ and $<111>$ directions [32], it

Table 3 - Calculated CSL boundary fractions in the gamma phase.

CSL boundaries for the gamma phase-volume fraction [\%]

$\Sigma 3 \quad$ Total between $\Sigma 3$ and $\Sigma 17$

$\begin{array}{lll}\text { Initial } & 68.2 & 72.7\end{array}$

Medium deformation $\quad 14.4 \quad 21.2$

$\begin{array}{lll}\text { Large deformation } \quad 4.2 & 10.9\end{array}$



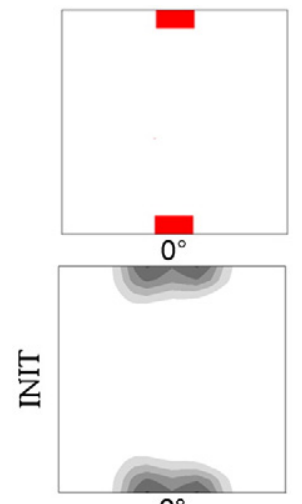

$0^{\circ}$

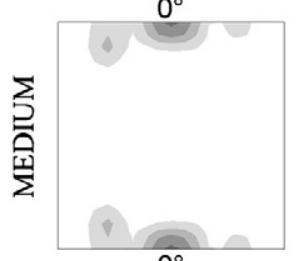

$0^{\circ}$

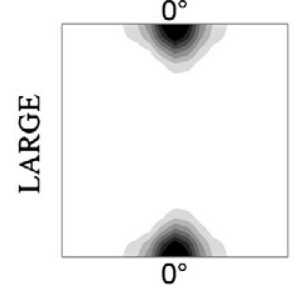

Cube Rot

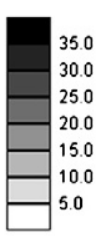

$\varphi_{1}(0-90)$ DEG

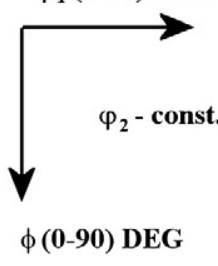

Fig. 10 - Experimental textures for various degrees of deformation for the alpha phase-ODF sections $\left(\varphi_{2}=0^{\circ}, 45^{\circ}\right)$. is expected that the Cube, rotated Cube and Cu orientations will be stable during tension, whereas the Bs can be characterized as metastable, which is to say, evolving slowly during tension, and the $\mathrm{S}$ is completely unstable, in other words, expected to rotate towards the Bs component. Thus, because of the stability of most texture components during tension in both phases, both textures reinforce during deformation. The volume fractions of each component [21] were calculated as a function of deformation and are plotted in Fig. 12. The trends observed confirm what has previously been said about the stability of orientations during tensile deformation: the rotated cube in the alpha phase and the brass, RW and cube in the gamma phase are reinforced during deformation. The $\mathrm{S}$ and copper components exhibit inverse behavior. The RW component in the gamma phase grows continuously, but at a low rate.

\section{Conclusion}

A detailed analysis of the EBSD data measured at different levels of strain in a duplex material demonstrates that the two phases behave differently during deformation. In the initial state, both phases have similar IQ distributions, which can be linked to a similar level of initial stored energy, close to 0 as a result of the previous annealing treatment. During deformation, the microstructural parameters under study evolve differently:

- The estimated deformed volume fraction is higher in the gamma phase than in the alpha phase;
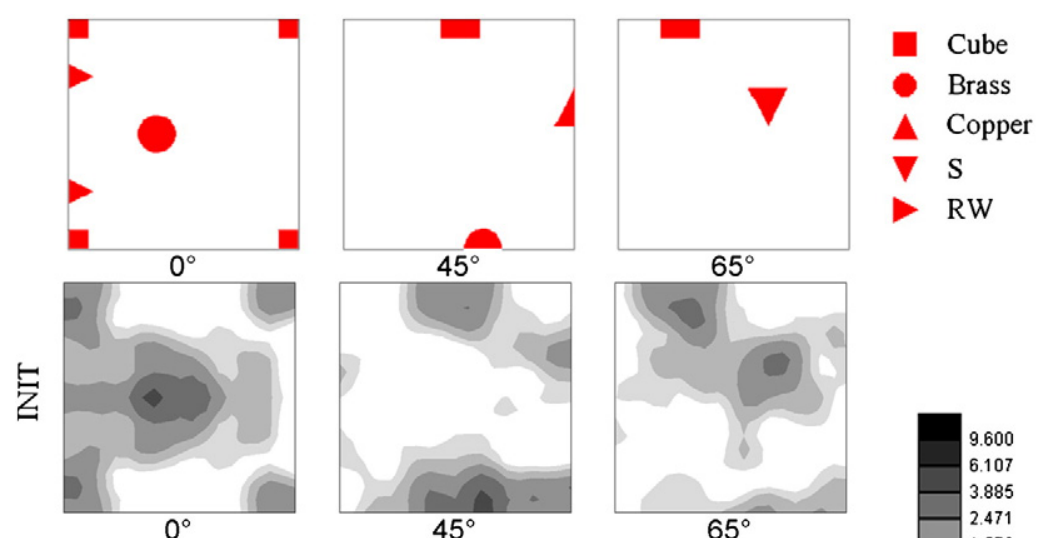

$45^{\circ}$
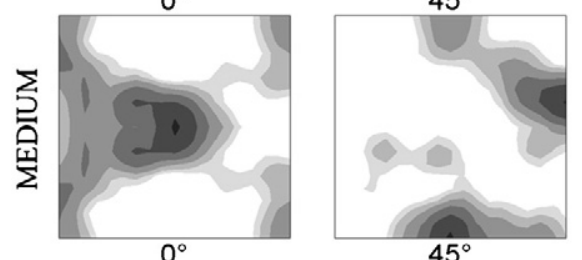

$45^{\circ}$
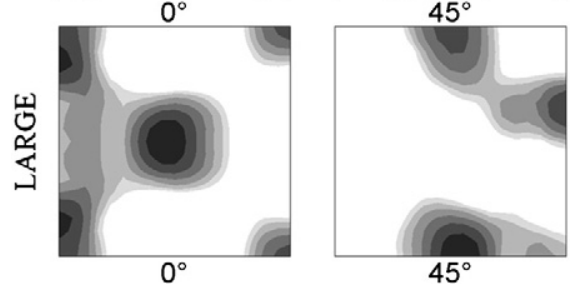

$45^{\circ}$

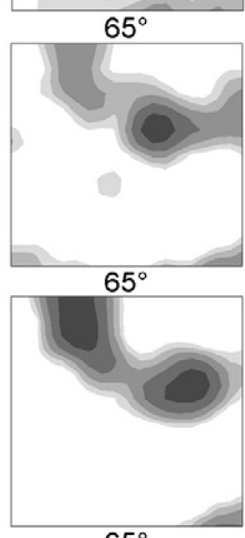

$65^{\circ}$
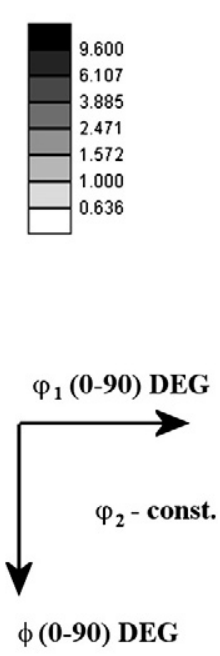

Fig. 11 - Experimental textures for various degrees of deformation for the gamma phase-ODF sections $\left(\varphi_{2}=0^{\circ}, 45^{\circ}\right.$ and $\left.65^{\circ}\right)$. 

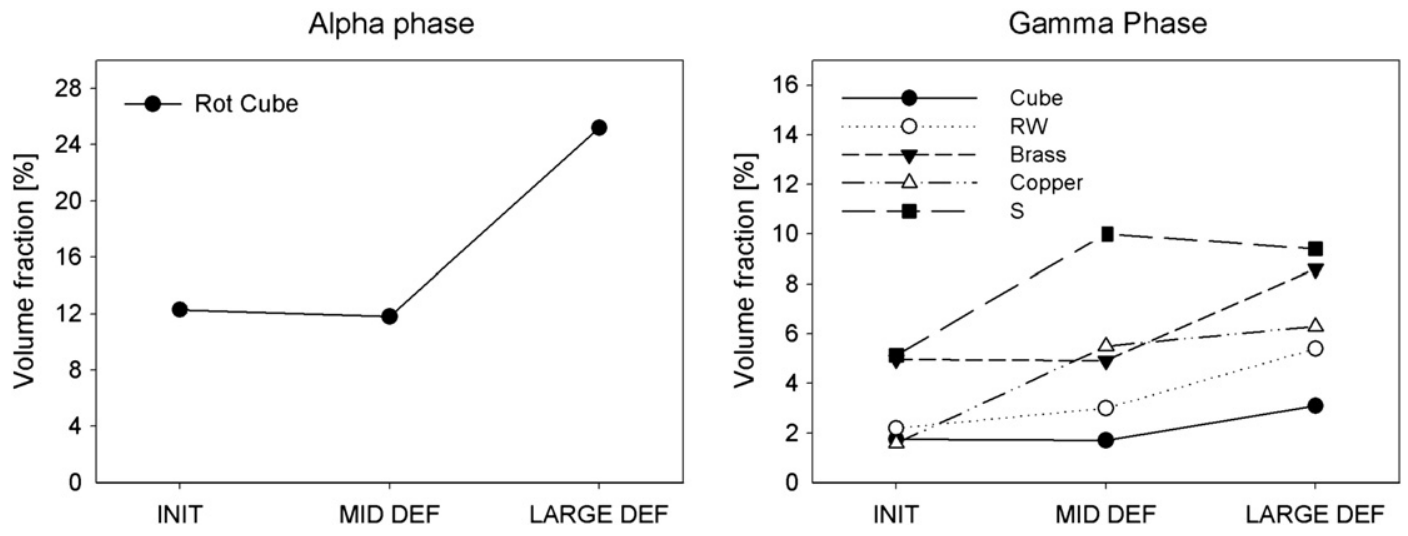

Fig. 12 - Volume fraction of ideal texture components for the alpha and gamma phases as a function of strain.

- The average Kernel misorientation also increases faster in the gamma phase than it does in the alpha phase.

These observations are all consistent with previous observations of a higher stored energy level in the gamma phase.

The grain boundary analysis based on the kernel average misorientation throws some light on the way in which both phases deform. The gamma grains, which are initially quite small as a result of previous recrystallization, deform more homogeneously than the initially large alpha grains, in which a strong internal substructure builds up during deformation.

From a texture point of view, the stability of most of the texture components in the two phases explains the slow texture evolution observed, as well as the evolution of the LAB in the gamma phase.

The marked difference between phases can be observed in terms of twins and CSL boundaries. The alpha phase is almost free from these features, whereas, in the initial state, many annealing twin boundaries are observed in the gamma phase. After high deformation, twins disappear but the total number of CSL boundaries between $\Sigma 3$ and $\Sigma 17$ is still well over $10 \%$ of all the boundaries. This may affect the mechanical behavior of the material.

This paper thus shows a number of different microstructural features in the behavior of the alpha and gamma phases during the deformation of a duplex steel. In terms of stored energy, internal grain structure, number of special boundaries and intensity of texture components, the magnitude of the differences observed varies with the degree of deformation. Control of the macroscopic level of strain together with the proportion of both phases can then be useful for controlling the final properties of the material.

\section{Acknowledgments}

This work was supported by the grant of the Polish National Scientific Center (NCN): 2011/01/D/ST8/07399 as well as by the Polish Ministry of Science and Higher Education (MNiSW).

\section{R E F E R E N C E S}

[1] Dupoiron F, Audouard JP. Duplex stainless steels: a high mechanical properties stainless steels family. Scand J Metal 1996;25:95-102.

[2] Nilsson JO. Super duplex stainless steels. Mater Sci Technol 1992;8:685-700.

[3] Charles J, Verneau M, Audouard J-P, Demars S. Some duplex applications: test results and practical experience. Proceedings of the Stainless Steel World Conference, Book 2. The Netherlands: KCI Publishing; 1999. p. 476-85.

[4] Mcirdi L, Baptiste D, Inal K, Lebrun J-L, Barbier G. J Appl Neutr Res 2000;9(217).

[5] Moverare JJ, Oden M. Deformation behaviour of a prestrained duplex stainless steel. Mater Sci Eng A 2002;337(1-2):25-38 25.

[6] Dakhlaoui R, Braham C, Baczmanski A, Wroński S, Wierzbanowski K, Oliver EC. Effect of residual stresses on mechanical properties of duplex stainless steel studied by diffraction and self-consistent modelling. Mater Sci Forum 2006;524-525:185-90.

[7] Dakhlaoui R, Baczmański A, Braham C, Wronski S, Wierzbanowski K, Oliver EC. Effect of residual stresses on individual phase mechanical properties of austeno-ferritic duplex steel. Acta Mater 2006;54:5027-39.

[8] Baczmański A, Gaj A, Le Joncour L, Wroński S, François M, Panicaud B, et al. Study of stress localisation in polycrystalline grains using self-consistent modelling and neutron diffraction. Phil Mag 2012, doi:10.1080/14786435.2012.683542.

[9] EL Bartali A, Evrard P, Abuin V, Herenu S, Alvarez I, Aramas AF, et al. Strain heterogeneities between phases in a duplex stainless steel. Comparison between measures and simulation. Procedia Eng 2010;2:2229-37.

[10] Zielinski W, Swiatnicki W, Barstch M, Messerschmidt U. Non-uniform distribution of plastic strain in duplex steel during TEM in situ deformation. Mater Chem Phys 2003;81: 476-9.

[11] Gironès A, Villechaise P, Mateo A, Anglada M, Méndez J. EBSD studies on the influence of texture on the surface damage mechanisms developed in cyclically loaded aged duplex stainless steels. Mater Sci Eng A 2004;387-389: 516-21.

[12] El Bartali A, Aubin V, Sabatier L, Villechaise P, Degallaix-Moreuil S. Identification and analysis of slip systems activated during low-cycle fatigue in a duplex stainless steel. Scr Mater 2008;59(12):1231-4. 
[13] Fréchard S, Martin F, Clément C, Cousty J. AFM and EBSD combined studies of plastic deformation in a duplex stainless steel. Mater Sci Eng A 2006;418:312-9.

[14] Tarasiuk J, Ph Gerber, Bacroix B. Estimation of recrystallized volume fraction from EBSD data. Acta Mater 2002;50:1467-77.

[15] Lacombe P, Baroux B, Béranger G. Les aciers inoxydables, Les éditions de physique. France: Les Ulis; 1990.

[16] Wu J, Wray PJ, Garcia CI, Hua M, Deardo AJ. Image Quality Analysis: A New Method of Characterizing Microstructures. ISIJ Int 2005;45:254-62.

[17] Gerber Ph, Tarasiuk J, Chiron R, Bacroix B. Estimation of the recrystallized volume fraction from local misorientation calculations. Arch Metall 2005;5:747.

[18] Lu H, Sivaprasad P, Davies CHJ. Treatment of misorientation data to determine the fraction of recrystallized grains in a partially recrystallized metal. Mater Charact 2003;51:293-300.

[19] Bunge HJ. Mathematische Methoden der Textureanalyse. Berlin, Germany: Akademie-Verlag; 1969.

[20] Bunge $\mathrm{H}$. Texture analysis in material science. UK: Butterworths London; 1982.

[21] Cho JH, Rollett A, Oh K. Determination of volume fractions of texture components with standard distributions in Euler space. Metall Mater Trans 2004:1073-5623.

[22] Wroński S, Baczmański A, Dakhlaoui R, Braham C, Wierzbanowski K, Oliver EC. Determination of stress field in textured duplex steel using TOF neutron diffraction method. Acta Mater 2007;55:6219-33.

[23] Le Joncour L, Panicaud B, Baczmański A, Francois M, Braham C, Paradowska A, et al. Damage in duplex steels studied at mesoscopic and macroscopic scales. Mech Mater 2010;42(12): 1048-63.
[24] Baczmanski A, Le Joncour L, Panicaud B, Francois M, Braham C, Paradowska AM, et al. Neutron time-of-flight diffraction used to study aged duplex stainless steel at small and large deformation until sample fracture. J Appl Cryst 2011;44: 966-82.

[25] Wierzbanowski K, Baczmański A, Wroński S, Braham C, Lodini A. "Tuning" of deformation models by residual stress measurements. Arch Metall Mater 2005;50:457-64.

[26] Badji R, Bacroix B, Bouabdallah M. Texture, microstructure and anisotropic properties in annealed 2205 duplex stainless steel welds. Mater Charact 2011;62:833-43.

[27] Nesterova EV, Bacroix B, Teodosiu C. Microstructure and texture evolution under strain-path changes in low-carbon intersitital-free steel. Metall Mater Trans 2001;32A:2527-38.

[28] Kang J-Y, Bacroix B, Réglé H, Oh KH, Lee H-C. Effect of deformation mode and grain orientation on misorientation development in a body-centered cubic steel. Acta Mater 2007;55:4935-44.

[29] Lchockey EM, Palumbo G, Lin P. Metall Mather Trans A 1998;29A:3069-79.

[30] Watanabe T, Tsurekawa S, Kobayashi S, Yamaura S. Structure-dependent grain boundary deformation and fracture at high temperatures. Mater Sci Eng A 1993:140-7.

[31] Lin P, Palumbo G, Erb U, Aust KT. Influence of grain character distribution on sensitization and intergranular corossion on alloy 600. Scr Metall Mater 1995;33:1387-92.

[32] Poudens A, Bacroix B, Bretheau Th. Influence of microstructure and particle concentrations on the development of extrusion textures in metal matric composites. Mater Sci Eng 1995;A196: 219-28. 